Gilmara Oliveira Machado", André Luis Christoforo², Marilia Silva Bertolini, ${ }^{3, *}$, Carlos Cezar Cavassin Diniz ${ }^{1}$, Felipe Nogueira Silva ${ }^{1}$, Fernanda Paula Szekut ${ }^{1}$, Fábio Gomes Matos $^{1}$

\title{
Avaliação da qualidade energética e ambiental de fogão à lenha portátil para a cidade de Irati/Pr
}

\begin{abstract}
RESUMO
Este trabalho realizou a construção e teste de um fogão à lenha portátil com chaminé acoplada. O fogão proposto tem eficiência média de 6,4\% enquanto que para os fogões residenciais de Irati/PR se apresentam na faixa de 2,9 a 4,6\%. Utilizou-se como combustível lenha de Pinus taeda, com 9,6\% de teor de umidade e como isolante térmico da câmera de combustão, folhelho que é um solo estratificado característico da cidade de Irati. O fogão portátil apresentou potência de 337,4 W; consumo de combustível de 1,2 kg/h e como teores de gases de combustão aproximadamente 0,3 Nm3/kg de CO2; 0,03 Nm3/kg de CO e 2,5 10-5 Nm3/ kg para SO2. A concentração de CO médio $(160 \mathrm{mg} / \mathrm{m3})$ e máximo $(200 \mathrm{mg} / \mathrm{m3})$ bem como de exposição ao gás $(587 \mathrm{~h}-\mathrm{mg} / \mathrm{m3})$, para três horas de uso diário do fogão em uma cozinha hipotética, se apresentaram estatisticamente equivalentes aos dos fogões tradicionais e com limiares $82 \%$ superior aos recomendados pela OMS, indicando potencial impacto à saúde do usuário se o mesmo for utilizado sem chaminé. Desta forma, além de ser de baixo custo, o fogão proposto apresenta resultado bastante promissor quanto à eficiência.
\end{abstract}

Palavras-chaves: fogão à lenha, Irati/PR, eficiência energética.

\section{Energetic and enviromental performance of portable cookstove for Irati city, Paraná State}

\begin{abstract}
The mean purpose of this paper was the construction and testing of a portable wood stove. The proposed stove has an average efficiency of 6,4 \%, higher than the house stoves, that range from 2,9 to 4,6\%, in Iratil PR. The fuel wood is Pinus taeda, with 9,6\% moisture content. Folhelho stratified soil is used as thermal insulation of the combustion chamber. The thermal power of portable stove is 337,4 W; fuel consumption is $1.2 \mathrm{~kg} / \mathrm{h}$ and the levels of gases are $0.3 \mathrm{Nm}^{3} \mathrm{CO}_{2} / \mathrm{kg}, 0.03 \mathrm{Nm}^{3} \mathrm{CO} / \mathrm{kg}$ and $2.510^{-5} \mathrm{Nm}^{3} \mathrm{SO}_{2} / \mathrm{kg}$. The average concentration of $\mathrm{CO}\left(160 \mathrm{mg} / \mathrm{m}^{3}\right)$ and maximum $\left(200 \mathrm{mg} / \mathrm{m}^{3}\right)$ as well as gas exposure $\left(587 \mathrm{~h}-\mathrm{mg} / \mathrm{m}^{3}\right)$ for three hours of use of the stove into a hypothetical kitchen are all statistical similar to traditional stoves, indicating potential impact on user's health if used without flue or hood, additionally they are all about $82 \%$ higher than the thresholds recommended by WHO. Thus in addition to being low cost, the proposed stove has a very promising result in efficiency.

Keywords: wood stove, Irati-PR, energy efficiency.
\end{abstract}

\footnotetext{
*Autora para correspondência

${ }^{1}$ Universidade Estadual do Centro-Oeste (UNICENTRO);

${ }^{2}$ Universidade Federal de São Joao del-Rei (UFSJ);

${ }^{3}$ Universidade de São Paulo (USP); *email: marilia.bertolini@usp.br
} 


\section{INTRODUÇÃO}

Combustão é definida como uma reação química de oxidação exotérmica, que gera energia na forma de calor, ruído e luz. A reação se estabelece entre uma substância combustível (madeira ou lenha) e o oxigênio (geralmente do ar), com uma fonte inicial de calor atuante no combustível (energia de ativação do processo) e subsequente reação em cadeia, que gera energia térmica adicional, propiciando a queima contínua autossustentada. $\mathrm{Na}$ falta de combustível, do oxigênio ou da não ocorrência da reação em cadeia, a combustão não ocorre, ou se já existente, se anula. A combustão direta é a forma mais prática e mais fácil de utilização da madeira como energético, apresentando alta eficiência, da ordem de $90 \%$, na conversão da energia química em energia térmica, ou seja, calor (Fengel e Wegener, 1984).

O conhecimento da composição química da madeira é fundamental para o entendimento de seu comportamento como combustível. Os elementos químicos responsáveis pela liberação de calor são carbono, hidrogênio e enxofre. A qualidade do combustível é dada pelos elementos carbono e hidrogênio. A fração incombustível, que não fornece calor durante a combustão, é devida à presença de umidade, cinzas, oxigênio e nitrogênio.

Em termos gerais, as madeiras de coníferas são mais energéticas por apresentarem maior teor de carbono (50-53\%) que as folhosas (47-50\%) devido ao seu maior conteúdo de lignina e extrativos. Todas as espécies contêm em torno de $6 \%$ de hidrogênio. A porcentagem de oxigênio fica na faixa de 40 a $44 \%$, a de enxofre menos que $0,1 \%$ e nitrogênio de 0,1 a $0,2 \%$. As cinzas, em torno de $1 \%$, são óxidos minerais formados durante a combustão, onde os íons inorgânicos se oxidam e volatilizam ou formam partículas minerais de vários tamanhos. A presença de grande concentração de oxigênio na madeira faz com que a sua queima requeira menos oxigênio do ar, porém diminui a quantidade de energia liberada na combustão, reduzindo seu teor energético (Ragland et al. 1991).

Quando a combustão se processa de maneira completa (estequiométrica) máxima energia térmica é gerada; o carbono é convertido em gás carbônico, o hidrogênio em água e o enxofre em dióxido de enxofre. O baixo teor de enxofre e cinzas da madeira evidencia que esta reação não gera compostos tão tóxicos aos seres humanos ou que possam impactar significativamente o meio ambiente, uma vez que o carbono consumido na queima, para gerar gás carbônico, foi inicialmente armazenado pela árvore por meio da reação de fotossíntese. $\mathrm{Na}$ equação1, temos um exemplo da combustão completa da madeira de eucaliptos com oxigênio do ar $\left(\mathrm{O}_{2}+\right.$ $3,76 \mathrm{~N}_{2}$ ), com $30 \%$ de umidade (W) e composição elementar, na base úmida, de $34,30 \%$ de carbono (C), 4,11\% de hidrogênio $(\mathrm{H}), \quad 30,78 \%$ de oxigênio $(\mathrm{O}), \quad 0,21 \%$ de nitrogênio $(\mathrm{N}), 0,007 \%$ de enxofre $(\mathrm{S})$ e $0,504 \%$ de cinzas (A);supondo que o nitrogênio é inerte no processo e gera apenas gás nitrogênio $\left(\mathrm{N}_{2}\right)$.

$$
\begin{gathered}
\left(2,86 \mathbf{C}+4,11 \mathbf{H}+1,92 \mathbf{O}+0,02 \mathbf{N}+2,1910^{-4} \mathbf{S}+\mathbf{W}+\mathbf{A}\right)+2,93\left(\mathbf{O}_{\mathbf{2}}+\mathbf{3 , 7 6} \mathbf{N}_{2}\right) \rightarrow 2,86 \mathbf{C O}_{2}+ \\
2,05 \mathbf{H}_{2} \mathbf{O}+2,1910^{-4} \mathbf{S O}_{\mathbf{2}}+\mathbf{W}+\mathbf{A}+11,02 \mathbf{N}_{\mathbf{2}}
\end{gathered}
$$

(Equação 1)

A combustão da madeira ocorre com emissão de grandes quantidades de voláteis decorrente de uma etapa prévia de pirólise das macromoléculas, gerando produtos orgânicos de baixa massa molar que se misturam ao oxigênio do ar. Desta forma, a queima da madeira ocorre em etapas consecutivas e bem nítidas. Inicialmente há um pré-aquecimento que fornece a energia de ativação necessária ao processo. Em temperaturas na faixa de 150 a 350 ${ }^{\circ} \mathrm{C}$ ocorre uma rápida degradação térmica (pirólise) dos polissacarídeos (polioses e celulose), com grande emissão de voláteis (fumaça) e formação de chama. Como a madeira é composta, em média, por $70 \%$ de polissacarídeos, sob a ação do calor, três quartos de seu peso é volatilizado nesta etapa da combustão. A lignina, que constitui em torno de $25 \%$ da composição da madeira, por ter uma natureza química entrecruzada, se degrada lentamente, em uma ampla faixa de temperatura (de 200 a $500{ }^{\circ} \mathrm{C}$ ) e sem grandes reduções em sua massa residual, (Lora e Venturini, 2012).

Os produtos da pirólise da lignina são principalmente alcatrão e carvão vegetal. Com a extinção da chama dos voláteis, a madeira torna- 
se uma massa sólida composta de carvão e cinzas (coque). O coque é um resíduo resistente à degradação térmica e sua combustão constitui a etapa de maior duração do processo. É um material rico em carbono, que queima sem fazer fumaça (combustão incandescente) e; portanto, sem formação de chamas, de forma lenta, em temperaturas acima de $600^{\circ} \mathrm{C}$, desprendendo altas intensidades de calor em pontos específicos e formando como resíduo final, as cinzas (Cortez et al. 2009).

Segundo dados do Balanço Energético Nacional (BEN, 2013), a lenha tem uma participação significativa de $6,5 \%$ no consumo final de energia por fonte, sendo que no setor residencial a madeira é utilizada principalmente para a cocção de alimentos e em menor escala, principalmente em regiões de clima temperado, no aquecimento domiciliar (Rosillo-Calle et al. 2005; Seixas et al. 2006). No contexto de consumo de energia térmica pelas famílias, a lenha tem participação de $27,2 \%$, equivalente ao do gás liquefeito de petróleo de $26,9 \%$, que segundo Brito (2007), vem sendo o substituto natural na maioria das residências urbanas e para o qual, ao contrário da madeira, políticas oficiais de incentivos sempre se fizeram presentes.

A obtenção de energia da biomassa é realizada tradicionalmente por meio da queima direta (combustão) da lenha ou em menor escala do carvão vegetal, em equipamentos térmicos denominados de "fogões à lenha". Porém, a eficiência desses fogões, que pode variar de $5 \%$ a $30 \%$, depende da taxa de conversão da energia da lenha em calor, da tecnologia e do tipo de construção do equipamento, (Nogueira e Lora, 2003). Adicionalmente, é necessário um excesso de ar da ordem de 110 a $130 \%$ para que a combustão seja processada de forma completa; como os fogões à lenha não operam com excesso de ar, a consequiência imediata é a ocorrência constante de combustão incompleta (Lora e Venturini, 2012).

A combustão incompleta da madeira produz emissões de muitas substâncias tóxicas na atmosfera ou no ambiente onde o fogão está instalado. Os compostos mais frequentemente gerados compreendem os materiais finamente particulados (aerossóis, 7 a $30 \mathrm{~g} / \mathrm{kg}$ ), fuligem $(0,3$ a $5 \mathrm{~g} / \mathrm{kg})$, compostos orgânicos voláteis de natureza ácida $(1,8$ a 2,4 g/kg) e aromática (7 a 27 g/kg), monóxido de carbono (80 a 370 g/kg) e resíduos minerais. $\mathrm{O}$ composto orgânico volátil mais comum formado na queima incompleta da madeira é o metano $\left(\mathrm{CH}_{4}, 14\right.$ a $\left.25 \mathrm{~g} / \mathrm{kg}\right)$. Outro poluente bastante significativo é o monóxido de carbono (CO). O CO é um forte indicativo de combustão incompleta, sendo altamente tóxico e de grande impacto na saúde do usuário de fogões à lenha (Air Quality Wood Cooking Stove, 2013).

Os fogões à lenha convencionais apresentam uma baixa eficiência energética, em torno de $7 \%$ na região Sudeste-Sul do Brasil. Borges (1997) relata que a ineficiência dos fogões potencializa a emissão de voláteis tóxicos, tais como o monóxido de carbono, além de promover um grande consumo de madeira. Adicionalmente, há uma grande ocorrência de desflorestamento, uma vez que a maioria da lenha utilizada não provém de florestas plantadas e sim de coletas manuais em matas nativas.

Devido a todos os inconvenientes que um fogão tradicional pode apresentar, um fogão mais eficiente e que gere menos voláteis tóxicos propicia uma combustão mais limpa, bem como economia financeira e de esforço físico da família para a coleta da lenha e seu armazenamento. O menor consumo de lenha gera por fim uma diminuição no desmatamento.

Esta pesquisa teve por objetivo principal construir um fogão à lenha portátil e avaliar sua qualidade em termos de eficiência, potência, consumo de lenha e liberação de voláteis. Adicionalmente, por meio de uma simulação teórica de uso em uma cozinha hipotética, estimar a concentração e exposição ao gás tóxico $\mathrm{CO}$ em condições reais de uso. A pesquisa foi embasada em dados da população das áreas periféricas e rurais da cidade de Irati/PR, que ainda faz uso freqüente de fogões à lenha (Lau et al., no prelo 2013). Por fim, os resultados obtidos nesta pesquisa foram comparados com os obtidos por Lau et al. (no prelo 2013) no qual os autores citados determinaram a eficiência energética de três modelos de fogões à lenha metálicos característicos das residências unifamiliares da cidade de Irati/Pr.

\section{MATERIAL E MÉTODOS}

O fogão metálico portátil foi construído a partir de sucatas adquiridas em ferro velho da cidade de Irati/PR sendo, dessa forma, totalmente feito de materiais reutilizáveis, cumprido desta forma o objetivo de ser acessível à comunidade como 
um todo. $O$ fogão tem 27741,83 $\mathrm{cm}^{3}$ de capacidade, com volume ocupado pelo isolante de $22025,03 \mathrm{~cm}^{3}$ e pela câmera de combustão de $5716,80 \mathrm{~cm}^{3}$. O isolante apresenta densidade de $2,9 \mathrm{~g} / \mathrm{cm}^{3}$. A câmera de combustão tem formato triangular, para obtenção de uma maior razão arcombustível, com abertura lateral para entrada adicional de ar. Utilizou-se como isolante térmico folhelho, solo característico da cidade de Irati. A Figura 1 ilustra as formas e dimensões das partes constituintes do fogão construído.

O fogão a lenha portátil é apresentado na Figura 2 , onde se verifica as dimensões de cada um dos componentes constitutivos, com destaque para a câmera de combustão que foi projetada com uma capacidade volumétrica que favorecesse uma melhor mistura ar/combustível. Como medida de segurança, acoplou-se uma chaminé com o intuito de melhorar a canalização e remoção dos voláteis tóxicos gerados na combustão incompleta da madeira. Na figura 2, se verifica também a baixa emissão de voláteis durante a queima da lenha, disposta sobre uma grelha, dentro da câmera de combustão isolada termicamente. A lenha utilizada é de Pinus taeda, com 9,6\% $\%$ 0,8 de teor de umidade, sendo proveniente do comércio local da cidade de Irati/PR.

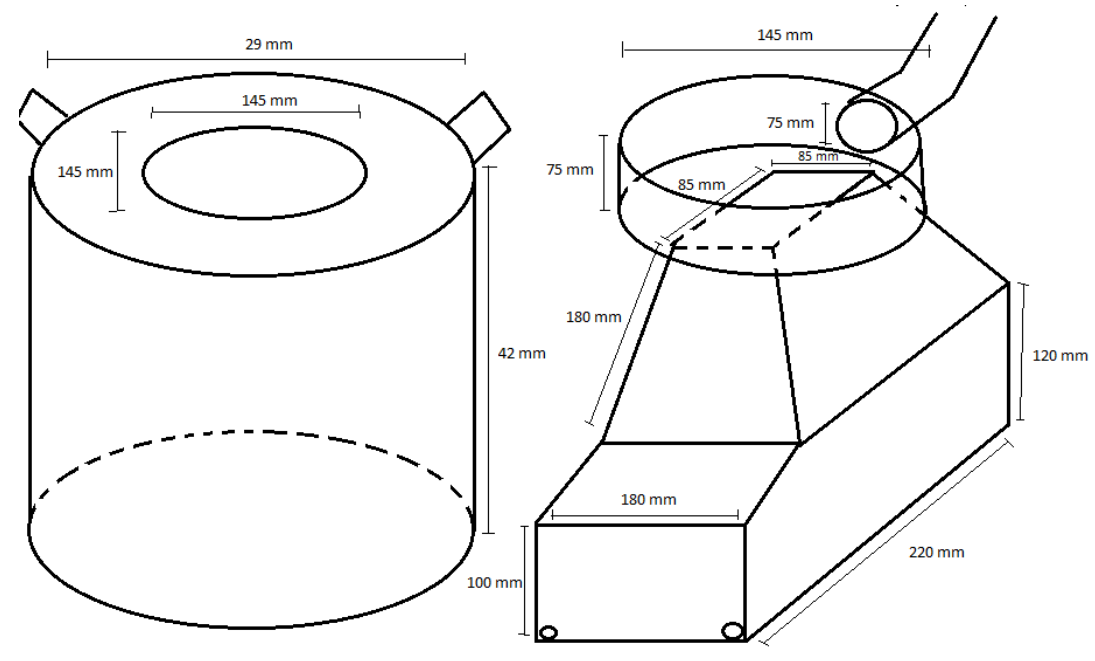

Figura 1. Dimensões do fogão à lenha portátil.

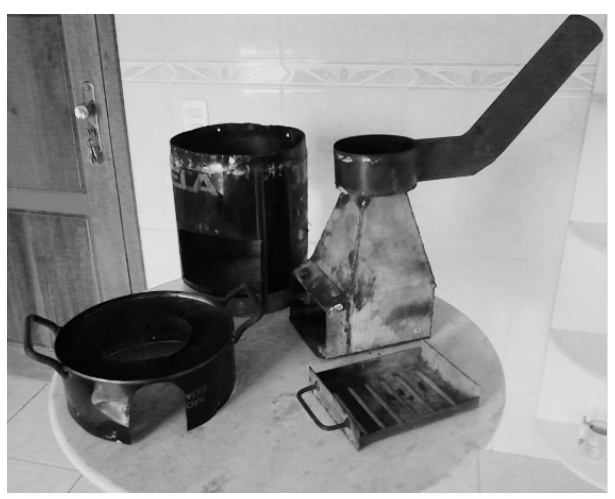

A

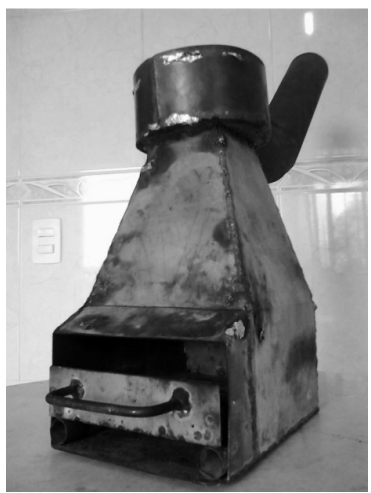

B 


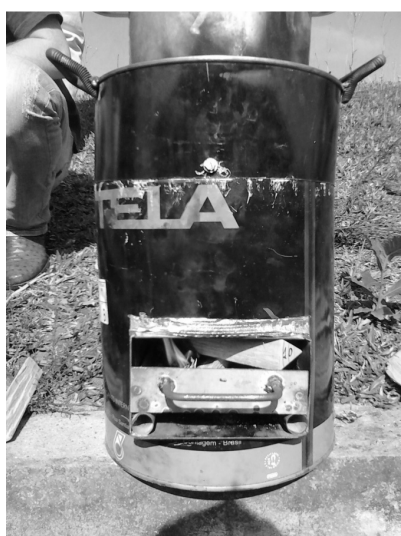

C

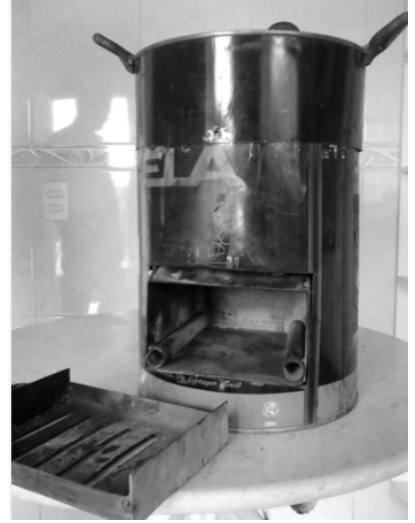

$\mathrm{D}$

Figura 2. Fogão à lenha portátil com baixa emissão de voláteis.

Para a determinação do teor de umidade da madeira (base seca) utilizou-se o método de secagem em estufa, que consistiu em se colocar quatro toretes, representativos da amostra, na estufa regulada para $105^{\circ} \mathrm{C}$, com pesagens sucessivas até obtenção de massa constante. $\mathrm{O}$ teor de umidade (U) é fornecido pela Equação 1 (BRITO, 1993 e 2004), sendo $m_{i}$ a massa inicial da amostra e $m_{s}$ a massa seca.

$$
U=\frac{m_{i}-m_{s}}{m_{s}} \cdot 100(\%)
$$

(Equação 2)

O poder calorífico superior (PCS) considerado foi de 20,02 $\mathrm{MJ} / \mathrm{kg}$, dado obtido da literatura especializada para o gênero Pinus (Cortez et al., 2009). Estimou-se o valor do poder calorífico inferior (PCI) da lenha através da Equação 3, considerando a porcentagem de hidrogênio $(\mathrm{H}) \mathrm{da}$ madeira igual a 6\% (BRITO, 1993).

$$
P C I=P C S-600 \cdot\left(\frac{9 H}{100}\right)(k c a l / k g)
$$

(Equação 3)

De posse do valor do teor de umidade da lenha (U) e do poder calorífico inferior (PCI), o poder calorífico líquido (PCU) foi calculado pela Equação 4 (BRITO, 1993).

$$
P C U=P C I \cdot(1-U)-600 \cdot U(\mathrm{kcal} / \mathrm{kg})
$$


(Equação 4)

A eficiência de um fogão à lenha é a relação adimensional entre o efeito energético útil e o consumo de energia do combustível. A eficiência foi calculada com base na avaliação da quantidade de calor absorvido pela água em uma panela metálica ( $Q_{\text {útil }}$ ) e a quantidade de calor fornecida pelo combustível ( $\left.\mathrm{Q}_{\text {lenha }}\right)$ (NOGUEIRA e LORA, 2003).

Foram efetuadas cinco repetições consecutivas. Cada ensaio apresentou duração de 20 minutos e consistiu em pesar certa quantidade de lenha antes e depois do aquecimento de $2 \mathrm{~kg}$ de água, sem ocorrência de ebulição, em uma panela de alumínio com tampa de 3 litros de capacidade. No decorrer do tempo de cada ensaio, a cada 5 minutos foram feitas medidas de temperatura com o auxílio de um termômetro.

Inicialmente o fogão foi aceso para realizar seu aquecimento. Após o pré-aquecimento do fogão, iniciou-se o primeiro teste onde a panela permaneceu o tempo todo tampada, exceto no momento de medição da temperatura. A panela só foi colocada no fogão quando a madeira iniciou o seu processo de queima. Com auxílio da Equação 5, o calor útil absorvido pela água na panela $\left(Q_{u u ́ t i l}\right)$ foi calculado, sendo $\mathrm{m}_{\mathrm{H} 2 \mathrm{O}}$ a massa de água a ser aquecida $(\mathrm{kg}), \mathrm{C}_{\mathrm{H} 2 \mathrm{O}} \mathrm{o}$ calor específico da água $\left(\mathrm{kcal} / \mathrm{kg}^{\circ} \mathrm{C}\right)$ e $\Delta \mathrm{T}_{\mathrm{H} 2 \mathrm{O}}$ a diferença de temperatura entre o início e o final do ensaio $\left({ }^{\circ} \mathrm{C}\right)$.

$$
Q_{\text {útil }}=m_{H 2 O} \cdot C_{H 2 O} \cdot \Delta T_{H 2 O} \quad(\mathrm{kcal})
$$

(Equação 5)

Após 20 minutos de cada ensaio o fogo foi apagado a seco, e toda a lenha residual foi retirada para ser pesada. Para obter-se precisão na pesagem, os resíduos da queima foram retirados do fogão e armazenados em recipientes fechados de alumínio em caixas de isopor para resfriamento e em seguida pesados em balança semi-analítica. $O$ calor total fornecido pela queima da lenha $\left(\mathrm{Q}_{\text {lenha }}\right)$ foi calculado com o auxílio da Equação 6, sendo $m_{q}$ a massa de lenha consumida no aquecimento da água, diferença entre a massa de lenha inicial e a massa do resíduo da combustão, e $\mathrm{PCU}_{1}$ o poder calorífico líquido da lenha.

$$
Q_{\text {lenha }}=P C U_{l} \cdot m_{q}(k c a l)
$$

(Equação 6)

A eficiência do fogão (Ef) se obteve através do resultado da razão entre o calor absorvido pela água (calor útil) e a energia liberada pela lenha (Equação

7).

$$
E f=100 \cdot\left(\frac{Q_{u} t i l}{Q_{\text {lenha }}}\right)(k c a l)
$$


A potência calorífica do fogão está diretamente relacionada com o calor produzido pela lenha através do seu poder calorífico, tempo de queima da lenha $(\Delta \mathrm{T})$ e eficiência. A potência do fogão $(\mathrm{Pf})$ é dada pela Equação 8 , sendo $\mathrm{m}_{\mathrm{q}} \mathrm{a}$ massa de lenha queimada.

$$
P f=\frac{m_{q} \cdot P C U_{l} \cdot E f}{\Delta T}
$$

(Equação 8)

A maioria dos métodos utilizados para avaliar os fogões à lenha é baseada apenas no desempenho térmico do equipamento, ignorando as emissões de poluentes. Contudo, os fogões à lenha liberam grandes quantidades de voláteis e gases tóxicos, submetendo o usuário às exposições extremamente prejudiciais a saúde. Desta forma, foi realizada uma estimativa da quantidade de $\mathrm{CO}_{2}, \mathrm{SO}_{2}$ e $\mathrm{CO}$ liberados por fogões metálicos. Segundo dados da literatura, a quantidade média de CO liberado na queima incompleta da madeira em fogões à lenha metálicos equivale cerca de $10 \%$ do teor de gases provenientes da queima do carbono (JOSSI, 1989 e ZHANG et al., 1999). De posse dos valores da Análise Elementar, é possível apresentar a equação balanceada da combustão da lenha (Equação 10) e assim determinar os teores de $\mathrm{CO}, \mathrm{CO}_{2}$ e $\mathrm{SO}_{2}$ liberados na queima de um quilograma de combustível, para cada ensaio realizado, por meio da densidade dos gases na CNTP.

A Análise Elementar da lenha foi obtida da literatura especializada, (Cortez et al., 2009), base seca, consistindo em 49,25\% de carbono (C); 5,99 \% de hidrogênio (H); 44,36\% de oxigênio $(\mathrm{O}) ; 0,06 \%$ de nitrogênio $(\mathrm{N}) ; 0,03 \%$ de enxofre (S) e $0,30 \%$ de cinzas (A). A equação de combustão foi elaborada com a composição elementar na base de trabalho assumindo-se que todo o carbono presente na lenha reage durante a combustão produzindo apenas $\mathrm{CO}_{2}$ e $\mathrm{CO}$ (com conversão de $90 \%$ do carbono em $\mathrm{CO}_{2}$ e $10 \%$ em $\mathrm{CO})$ e que o enxofre é completamente convertido em $\mathrm{SO}_{2}$, o hidrogênio em $\mathrm{H}_{2} \mathrm{O}$ e nitrogênio em $\mathrm{N}_{2}$, a equação global da combustão de $100 \mathrm{~kg}$ de lenha de Pinus taeda no ar $\left(\mathrm{O}_{2}+3,76 \mathrm{~N}_{2}\right)$, na base de trabalho, com teor de umidade da lenha de $9,6 \% \pm 0,8$, é expressa pela equação 9 (JOSHI, V., et al.,1989 and ZHANG, J. et al., 1999).

$$
\begin{gathered}
3,69 \mathrm{C}+5,30 \mathrm{H}+2,48 \mathrm{O}+0,019 \mathrm{~N}+0,00028 \mathrm{~S}+1,67 \mathrm{H}_{2} \mathrm{O}+0,65+3,59\left(\mathrm{O}_{2}+3,76 \mathrm{~N}_{2}\right) \rightarrow 3,32 \mathrm{CO}_{2}+ \\
0,37 \mathrm{CO}+0,00028 \mathrm{SO} 2+2,65 \mathrm{H}_{2} \mathrm{O}+13,49 \mathrm{~N}_{2}+1,67 \mathrm{H}_{2} \mathrm{O}+0,65
\end{gathered}
$$

(Equação 9)

A combustão incompleta da madeira em ambientes fechados, como cozinhas, gera emissões de monóxido de carbono e assim pode resultar em altas concentrações de $\mathrm{CO}$ no meio. $\mathrm{O}$ método para predizer a concentração média $\left(\mathrm{C}_{\text {médio }}, \mathrm{em} \mathrm{mg} / \mathrm{m}^{3}\right)$, máxima $\left(\mathrm{C}_{\max }, \mathrm{em} \mathrm{mg} / \mathrm{m}^{3}\right)$ e potencial de exposição $\left(\mathrm{E}, \mathrm{em} \mathrm{h}-\mathrm{mg} / \mathrm{m}^{3}\right)$ ao $\mathrm{CO}$ foi baseado nos pressupostos da pesquisa de Zhang et al. (1999), onde assume-se que todo $\mathrm{CO}$ emitido provém somente do fogão que não apresenta chaminé ou exaustor. Adicionalmente, assume-se também que o $\mathrm{CO}$ se dilui homogeneamente na cozinha, sendo removido somente pela ventilação e renovação natural do ar ambiente. Nestas condições, a concentração média e máxima de $\mathrm{CO}$, bem como o potencial de Exposição ao gás, são dadas pelas equações 10,11 e 12 ; onde $\mathrm{F}(\mathrm{kg} / \mathrm{h})$ se refere a taxa de queima do combustível, Ef $(\mathrm{g} / \mathrm{kg})$ a quantidade de $\mathrm{CO}(\mathrm{g})$ por unidade de massa queimada de madeira $(\mathrm{kg}), \mathrm{t}(\mathrm{h})$ é o tempo de queima sendo representado por $\mathrm{T}$ para o período completo de queima, $\mathrm{V}\left(\mathrm{m}^{3}\right)$ é o volume da cozinha e $\mathrm{S}\left(\mathrm{h}^{-1}\right)$ a taxa de renovação natural do ar. Adotou-se um volume para a cozinha de $40 \mathrm{~m}^{3}$ (volume típico das cozinhas de Irati/PR), com taxa de renovação do ar de $15 \mathrm{~h}^{-1}$ (valor estimado para uma cozinha urbana). O valor de Ef (valor 
obtido da equação 10 de combustão incompleta) e $\mathrm{F}$ foram determinados com os dados experimentais, sendo $103,6 \mathrm{~g} / \mathrm{kg}$ e $1,2 \mathrm{~kg} / \mathrm{h}$, respectivamente. No tempo de uso do fogão, assumiu-se como uma hora o período de preparação de cada refeição (café da manhã, almoço ou jantar), totalizando três horas de uso diário.

$$
C_{\max }=\frac{F \times E f}{V \times S}\left(1-e^{-5 T}\right)
$$

(Equação 10)

$$
\mathrm{C}_{\text {medio }}=\frac{F \times E^{f}}{V \times S}\left(1+\frac{1}{S \times T}\left(e^{-S T}-1\right)\right)
$$

(Equação 11)

$$
E-\frac{F \times E F}{V \times S}\left(T-\frac{1}{S}\left(1-e^{-S T}\right)\right)
$$

(Equação 12)

Os dados foram avaliados com o uso da análise de variância (ANOVA) de Kruskal-Wallis (não paramétrica) e do teste de comparações múltiplas entre postos de Student-NewmanKeuls, com o auxílio do software BioEstat ${ }^{\circledR}$ versão 5.0. $\mathrm{O}$ nível de significância $(\alpha)$ estipulado para a ANOVA foi de $5 \%$, e a hipótese nula $\left(H_{0}\right)$ formulada consistiu na equivalência entre médias, implicando na não equivalência entre médias para a hipótese alternativa $\left(H_{1}\right)$. P-valor do teste de KruskalWallis superior ao nível de significância implica em aceitar $H_{0}$, refutando-a em caso contrário. Os resultados de eficiência energética, consumo de lenha, concentração e exposição ao CO desta pesquisa foram comparados com os obtidos no trabalho de Lau et al. (no prelo 2013), onde 3 modelos de fogões à lenha metálicos residenciais (Ref 1; Ref 2; Ref 3), da cidade de Irati/PR, foram avaliados. As respostas investigadas pela ANOVA foram a Eficiência, Potência, Massa Queimada, Gases liberados da Combustão $\left(\mathrm{CO}_{2} ; \mathrm{SO}_{2}, \mathrm{CO}\right)$, Concentração e Exposição ao $\mathrm{CO}$; sendo utilizadas cinco amostras por propriedade.

\section{RESULTADOS E DISCUSSÕES}

A Tabela 1 apresenta os resultados obtidos das propriedades energéticas investigadas, sendo $\bar{x}$ a média amostral e $\mathrm{S}$ o desvio padrão. $\mathrm{O}$ coeficiente de variação indica boa precisão experimental.

Tabela 1. Resultados de eficiência (Ef), potência calorífica (Pf), massa queimada (mq) e volume de gases da combustão $\left(\mathrm{CO}_{2}, \mathrm{CO}\right.$ e $\left.\mathrm{SO}_{2}\right)$ da lenha de Pinus taeda, 9,6\% $\%$ 0,8 de umidade.

\begin{tabular}{llllll}
\hline \multirow{2}{*}{$\mathrm{Ef}(\%)$} & $\mathrm{Pf}(\mathrm{W})$ & $\mathrm{m}_{\mathrm{q}}(\mathrm{kg})$ & $\mathrm{CO}_{2}$ & $\mathrm{CO}$ & $\mathrm{SO}_{2}$ \\
\cline { 3 - 5 } & & & $\left(\mathrm{Nm}^{3} / \mathrm{Kg}\right)$ \\
\hline
\end{tabular}




\begin{tabular}{|c|c|c|c|c|c|}
\hline \multicolumn{6}{|c|}{$\bar{x} \pm S$} \\
\hline $6,4 \pm 1$ & $337,4 \pm 31,9$ & $0,39 \pm 0,05$ & $0,3 \pm 0,04$ & $0,03 \pm 0,01$ & $2,510^{-5} \pm 3,510^{-6}$ \\
\hline \multicolumn{6}{|c|}{ CV $(\%)$} \\
\hline 15 & 9 & 14 & 14 & 14 & 14 \\
\hline
\end{tabular}

A Tabela 2 apresenta os resultados da ANOVA de Kruskal-Wallis e do teste de comparações múltiplas entre postos de Student-Newman-Keuls referente à comparação dos valores de eficiência da espécie de madeira aqui estudada (F Bas1) com os valores de eficiência dos fogões (Ref 1; Ref 2;

Tabela 2. Resultados da ANOVA de Kruskal-Wallis e do teste de comparações múltiplas entre postos de Student-Newman-Keuls. Agrupamento por eficiência (\%) do fogão pesquisado e dos fogões referências.

\begin{tabular}{ccccccc}
\hline \multirow{2}{*}{ H } & \multirow{2}{*}{ GL } & \multirow{2}{*}{ P-valor } & \multicolumn{4}{c}{ Agrupamento - Eficiência (\%) } \\
\cline { 4 - 7 } & & & F Bas1 & Ref1 & Ref2 & Ref3 \\
\hline 16,5543 & 3 & 0,0009 & A & C & C & B
\end{tabular}

* Médias seguidas pelas mesmas letras não diferem estatisticamente pelo teste de comparação entre postos de Student-Newman-Keuls.

Os resultados obtidos evidenciam uma boa qualidade do fogão à lenha aqui proposto, apresentando maior eficiência térmica que os fogões metálicos tradicionalmente utilizados na cidade de Irati/PR e de custo final muito mais acessível às famílias de baixa renda ou mesmo para agricultores que poderão utilizar o equipamento térmico quando se encontram em trabalho de campo.

Os fogões-referência (LAU et al., no prelo 2013) apresentam baixa eficiência no aproveitamento do combustível, decorrente principalmente da perda de calor para as paredes metálicas expostas aos gases de combustão. $\mathrm{O}$ isolamento da câmera de combustão, do protótipo proposto neste estudo, garantiu um melhor aproveitamento da energia útil, possibilitando maior concentração de calor na câmara de combustão.

A partir dos valores de calor útil médio $\left(Q_{\text {útil }}=\right.$ $96,7$ kcal $\pm 9,1)$ e poder calorífico líquido da lenha na condição de uso $(9,6 \% \pm 0,8$ de umidade) para o fogão à lenha portátil e utilizando a equação $\mathrm{m}_{\mathrm{q}}=$ $100 \times Q_{\text {util }} / E_{f} \times$ PCU já apresentada na metodologia (equação 8) é possível estimar o consumo de lenha $\left(\mathrm{m}_{\mathrm{c}}\right)$, bem como a área de plantio necessários em função da eficiência do fogão (Ef , em \%), para a espécie de Pinus taeda. A variação de massa de lenha consumida
Ref 3) avaliados no trabalho de Lau et al. (no prelo 2013), conforme anteriormente mencionado. Todos os fogões apresentaram uma baixa eficiência energética média de $2,9 \% \pm 0,3(\operatorname{Ref} 1)$, $2,6 \% \pm 0,5(\operatorname{Ref} 2)$ e $4,6 \% \pm 0,2(\operatorname{Ref} 3)$. 
importância de se operar com equipamentos térmicos mais eficientes. Um fogão mais eficiente propicia uma combustão mais completa e limpa, bem como economia financeira e de esforço físico da família para a coleta da lenha e seu armazenamento. O menor consumo de lenha gera por fim uma diminuição no desmatamento ou na necessidade de área plantada (Regueira, 2010; Brand, 2010).
Na Figura 3, também se observa uma tendência de diminuição da quantidade de lenha necessária na combustão com o aumento da eficiência. Esse resultado reforça a discussão do parágrafo anterior, mostrando que fogões mais eficientes consomem menos lenha e consequentemente promovem uma maior economia no uso do combustível.

Tabela 3. Quantidade de lenha (9,6\% de umidade) e área de plantio necessário ao fogão à lenha portátil comparado ao fogão a gás (eficiência de $50 \%$ ).

\begin{tabular}{cccccc}
\hline \multicolumn{2}{c}{ Eficiência $(\%)$} & \multicolumn{2}{c}{ Massa de lenha anual $(\mathrm{kg})$} & Área de plantio necessária (ha) \\
\hline $6,40 \%$ & $50 \%$ & 1336 & 171 & 37 & 5 \\
\hline
\end{tabular}
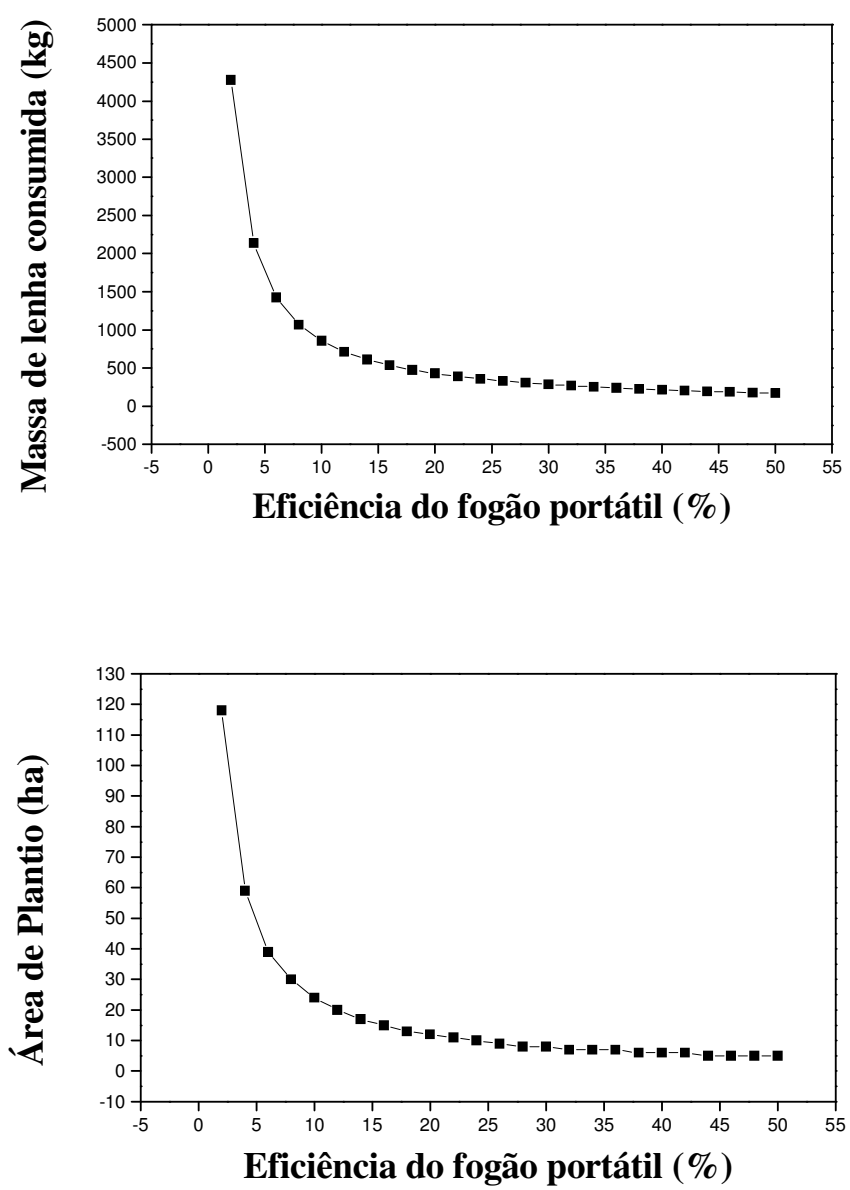

Figura 3. Lenha consumida e Área de plantio (9,6\% de umidade) versus eficiência do fogão à lenha portátil

Assim como a eficiência do fogão, as informações relativas à liberação de voláteis tóxicos na queima do combustível são importantes. Todos os fogões à lenha operam por meio de combustão incompleta, que além de liberar menos energia contida no combustível, gera muitos compostos tóxicos 
(Northcross et al. 2012). O fogão portátil apresenta menor potencial de risco à saúde do usuário, decorrente da menor liberação de voláteis na combustão e da presença de chaminé que direciona os gases para o exterior do ambiente onde o equipamento está instalado. Desta forma, se usado em interiores residenciais, apresenta uma menor liberação de gases tóxicos no meio, como o monóxido de carbono (Tab. 4), presente na fumaça no interior das cozinhas.

Segundo a Organização Mundial da Saúde e Normas Americanas, para um dia de exposição ao $\mathrm{CO}$, o valor limite recomendado é de $96 \mathrm{~h}$ $\mathrm{mg} / \mathrm{m}^{3}$. Os resultados apresentados tanto pelo fogão portátil como pelos fogões tradicionais são da ordem de $83 \%$ maior que o limite recomendado. Esse dado indica fortes evidências da grande toxicidade a que o usuário de fogão à lenha está exposto em ambiente residencial, caso não exista equipamentos (exaustor) ou dispositivos instalados (chaminé) na cozinha para remoção desses voláteis (Joshi et al. 1989; Zhang et al. 1999).

Tabela 4. Concentração e Exposição ao $\mathrm{CO}$ em ambiente interno (cozinha) hipotético para $3 \mathrm{~h}$ de consumo de lenha em fogão metálico sem chaminé ou exaustor.

\begin{tabular}{cccccc}
\hline & $\mathbf{F ~ ( k g / h )}$ & $\mathbf{E f}(\mathbf{g} / \mathbf{k g})$ & $\mathbf{C m a ́ x}(\mathbf{m g} / \mathbf{m 3})$ & Cmédio $(\mathbf{m g} / \mathbf{m 3})$ & $\mathbf{E}(\mathbf{h}-\mathbf{m g} / \mathbf{m 3})$ \\
\cline { 2 - 6 } & $\overline{\boldsymbol{x}} \pm \mathbf{S}$ & & $\overline{\boldsymbol{x}} \pm \mathbf{S}$ & $\overline{\boldsymbol{x}} \pm \mathbf{S}$ & $\overline{\boldsymbol{x}} \pm \mathbf{S}$ \\
\hline FBas1 & $1,2 \pm 0,2 \mathrm{~A}$ & 103,6 & $200 \pm 28 \mathrm{~A}$ & $160 \pm 22 \mathrm{~A}$ & $587 \pm 82 \mathrm{~A}$ \\
\hline Ref1 & $1,3 \pm 0,3 \mathrm{~A}$ & 99,4 & $220 \pm 53 \mathrm{~A}$ & $176 \pm 43 \mathrm{~A}$ & $645 \pm 157 \mathrm{~A}$ \\
\hline Ref2 & $1,3 \pm 0,1 \mathrm{~A}$ & 99,4 & $218 \pm 20 \mathrm{~A}$ & $175 \pm 16 \mathrm{~A}$ & $640 \pm 58 \mathrm{~A}$ \\
\hline Ref3 & $0,9 \pm 0,1 \mathrm{C}$ & 99,4 & $153 \pm 13 \mathrm{~B}$ & $123 \pm 10 \mathrm{~B}$ & $450 \pm 38 \mathrm{~B}$ \\
\hline
\end{tabular}

* Médias seguidas pelas mesmas letras não diferem estatisticamente pelo teste de comparação entre postos de Student-Newman-Keuls.

Neste estudo está sendo analisada apenas a emissão de $\mathrm{CO}$, porém sabe-se que a fumaça da queima da lenha também contém muitas outras substancias tóxicas ou potencialmente tóxicas, tais como, compostos cancerígenos como benzeno, 1,3-butadieno, além de dióxido de nitrogênio, aldeídos, hidrocarbonetos aromáticos e material particulado. Adicionalmente, a população de Irati/PR, principalmente da periferia e meio rural, ainda faz uso freqüente de fogões à lenha. Uma solução, que já vem sendo parcialmente tomada pela população, é o uso de chaminés que diminuam a exposição aos gases tóxicos em mais de $50 \%$, uma maior ventilação do ambiente por meio de janelas, portas e exaustores (não observados nos fogões tradicionais de Irati) e o uso de equipamentos térmicos mais eficientes (meta dessa pesquisa).

\section{CONCLUSÕES}

Há grande interesse em pesquisas que visem à avaliação da qualidade de fogões à lenha, bem como propostas de novos designs que apresentem maior eficiência e menor emissão de poluentes. $\mathrm{O}$ fogão à lenha deste estudo apresentou eficiência na faixa de $6,4 \% \pm 1$; potência de 337,4 $\pm 31,9$ W; consumo de combustível em torno de $1,2 \pm 0,2 \mathrm{~kg} / \mathrm{h}$ e teores de gases de aproximadamente $0,3 \pm 0,04 \mathrm{Nm}^{3} / \mathrm{kg}$ de $\mathrm{CO}_{2} ; 0,03 \pm 0,01 \mathrm{Nm}^{3} / \mathrm{kg}$ de $\mathrm{CO}$ e $2,510^{-5} \pm 3,5$ $10^{-6} \mathrm{Nm}^{3} / \mathrm{kg}$ para $\mathrm{SO}_{2}$.

Comparações com fogões metálicos residenciais de Irati/PR mostraram que o fogão proposto por essa pesquisa tem melhor desempenho no quesito eficiência, porém não verificou-se diferença estatística na concentração de $\mathrm{CO}$ médio $\left(160 \pm 22 \mathrm{mg} / \mathrm{m}^{3}\right)$ e máximo $\left(200 \pm 28 \mathrm{mg} / \mathrm{m}^{3}\right)$ bem como de Exposição ao gás $\left(587 \pm 82 \mathrm{mg} / \mathrm{m}^{3}\right)$ para três horas de uso em uma cozinha hipotética, quando comparado aos dados de dois fogões referência. Um dos fogões referência, apresentou menores valores que o protótipo proposto, sendo $\mathrm{C}_{\text {máx }}=153 \pm 13 \mathrm{mg} / \mathrm{m}^{3}, \quad \mathrm{C}_{\text {médio }}=123 \pm 10 \mathrm{mg} / \mathrm{m}^{3} \quad \mathrm{e}$ $E_{\text {máx }}=450 \pm 38 \mathrm{~h}-\mathrm{mg} / \mathrm{m}^{3}$. Adicionalmente, o fogão portátil libera uma quantidade $4 \%$ maior de monóxido de carbono no meio $(103,6 \mathrm{~g} / \mathrm{kg})$ que os fogões referência $(99,4 \mathrm{~g} / \mathrm{kg})$.

Os resultados obtidos nesta pesquisa evidenciam o desempenho superior do fogão proposto em termos de eficiência quando comparado com fogões metálicos tradicionais da cidade de Irati/PR, com baixo custo na sua construção e 
praticidade de uso. Independente do tipo de fogão utilizado, os desta pesquisa e os da cidade de Irati, verifica-se risco à saúde do usuário, com valores de Exposição ao monóxido de carbono, presente na fumaça no interior das cozinhas das casas, $83 \%$ acima do limite estipulado pela OMS.

\section{AGRADECIMENTOS}

Os autores agradecem ao professor Luiz Augusto Horta Nogueira, da UNIFEI, pela colaboração nas etapas iniciais dessa pesquisa.

\section{REFERÊNCIAS}

Air Quality Wood Cooking Stove. Disponível em: http://www.lhayul.com/jigme/pdf/melbourne_university /Air_quality_woodcooking_stove.pdf. Acesso em 24 set. 2013.

BEN 2013 (Balanço Energético Nacional): Relatório Síntese, Ano base 2012. Disponível em: $<$ https://ben.epe.gov.br/downloads/S\%C3\%ADntese\%2 0do\%20Relat\%C3\%B3rio\%20Final_2013_Web.pdf>.

Acesso em: 24 set. 2013.

BORGES, T. P. F. Fogão a lenha de combustão limpa. 1997. 121p. Dissertação (Mestrado em Engenharia Mecânica) - Faculdade de engenharia mecânica, Universidade Estadual de Campinas, Campinas, 1997.

BRAND, M. A. Energia de biomassa florestal. Rio de Janeiro: Interciência, 2010. 114p.

BRITO, J. O. Expressão da produção florestal em unidades energéticas. In: CONGRESSO FLORESTAL PANAMERICANO, 1, CONGRESSO FLORESTAL BRASILEIRO, 7, 1993, Curitiba, Anais...Curitiba: Sociedade Brasileira de Silvicultura, 1993, p.280-282.

BRITO, J. O. O uso energético da madeira. Estudos Avançados, v. 21, n. 59, p.185-193, 2007.

BRITO, J. O. , CINTRA, T. C. Madeira para energia no Brasil: realidade, visão estratégica e demanda de ações. Biomassa \& Energia, v. 1, n. 2, p. 157-163, 2004.

CORTEZ, L.A.B., LORA, E.E.S., GÓMEZ, E.O. Biomassa para energia. Campinas: UNICAMP, 2009. $735 \mathrm{p}$.

FENGEL, D., WEGENER, G. Wood: chemistry, ultrastructure, reactions. Walter de Gruyter: Berlin, 1984.

JOSHI, V., VENKATARAMAN, C., AHUJA, D. R.
Emissions from Burning Biofuels in Metal Cookstoves. Environmental Management, v. 13, n. 6, pp: 763-772, 1989.

LAU, P.C et al. Evaluation of the efficiency energy of wood stove from Irati Brazilian city. International Journal of Agriculture and Forestry, v.3, n.7. No prelo set. 2013.

LORA, E. E. S., VENTURINI, O. J. Biocombustíveis, Interciência: Rio de Janeiro, v.1, 588 p., 2012.

NOGUEIRA, L. A. H., LORA, E. E. S. Dendroenergia: fundamentos e aplicações. Rio de Janeiro, Interciencia, 2003. 200p.

NORTHCROSS, A. L. et al. Dioxin inhalation doses from wood combustion in indoor cookfires. Atmospheric Environment, v. 49, p. 415-418, 2012.

RAGLAND, K. W., AERTS, D. J., BAKER, A. J. Properties of Wood for Combustion Analysis. Bioresource Technology, v.37, p.161-168, 1991.

REGUEIRA, T. M. Comparação entre a eficiência de dois modelos de fogão a lenha e seus impactos sobre o desmatamento da caatinga. 2010. 38 p. Monografia (Bacharelado em Ciências Biológicas), Universidade Federal de Pernambuco, Pernambuco. 2010.

ROSILLO-CALLE, F., BAJAY, S., ROTHMAN, H. Uso da biomassa para produção de Energia na indústria brasileira. Campinas: UNICAMP, 2005. 448p.

SEIXAS, F., COUTO, L., RUMMER, R. B. Colheita De Plantios Arbóreos De Curta Rotação Para Energia. Biomassa \& Energia, v. 3, n. 1, p. 1-16, 2006.

SETTE JR, C. R., GEROMINI, M. P., NAKAJIMA, N. Y. Quantificação de biomassa do tronco de Pinus taeda em plantios com diferentes idades na região de Rio Negrinho-SC. Biomassa \& Energia, v. 1, n. 4, p. 343346, 2004.

ZHANG, J. et al. Carbon monoxide from cookstoves in developing countries: 1 . Emissionfactors. Chemosphere: Global Change Science, v. 1, pp: $353-$ 366, 1999.

Recebido: $28 / 07 / 2013$ Received: 07/28/2013

Aprovado: 22/10/2013

Approved: 10/22/2013 